\title{
MESSAGE FROM THE TECHNICAL PROGRAM CHAIRS
}

On behalf of the Technical Program Committee of the IEEE International Conference on Communications (ICC 2006), it is our pleasure to present the proceedings of this conference held in Istanbul. In addition to its long history and its unmatched natural beauty, Istanbul is also known as the point where two continents Europe and Asia - meet. While Istanbul bridging only two continents, ICC 2006 bridges even more continents through communications. This is already demonstrated in making the conference a reality by involving more than 3000 people from more than 50 countries in 5 continents.

We are proud to tell you that ICC 2006's program committee put together an outstanding program including 9 technical symposia and a number of executive panels, workshops and tutorials. ICC 2006 workshops address a number of areas and community of interest that are not covered within the technical symposia. Tutorials cover both fundamental and emerging technologies in the communications and networking areas. In addition, the executive panels organized by leading industry executives and addressing the hottest technical and business issues in the field of communications and networking. The panels, workshops, and tutorials along with the technical symposia bring top experts together from both the industry and academia to provide a wide set of perspectives, practices, and technical expertise.

We received more than 2600 submissions to the conference. This is the second highest submission number in the ICC and Globecom history. Over 1000 technical experts from all over the world participated in the peer review process. Based on the results of a rigorous peer review process, 983 best papers were selected for presentation and publication in ICC 2006 Proceedings resulting in about 39\% acceptance ratio. To encourage more interactions and fruitful discussions, this year, first time in ICC history, we arranged the presentation of some technical papers in the poster format. From the technical quality standpoint and the publication in the proceedings, ICC 2006 does not distinguish among papers regardless their presentation format during the conference. With 165 sessions featuring lecture style presentations and 17 sessions featuring poster style presentations, ICC 2006's 9 technical symposia cover a variety of areas ranging from wireless communications to optical networks.

The technical program of ICC 2006 would not have been possible without the tremendous volunteer efforts of the entire ICC 2006 technical program committee and organization committee. We are most grateful to the authors who submitted their work to ICC 2006, the symposia chairs and vice chairs, technical program committee members, the reviewers who have so diligently supported the peer review process, the workshop chairs who have worked so hard to organize the workshops, the technical program vice chairs, and everyone else who helped to put together this remarkable program for their time, dedication, and hard work.

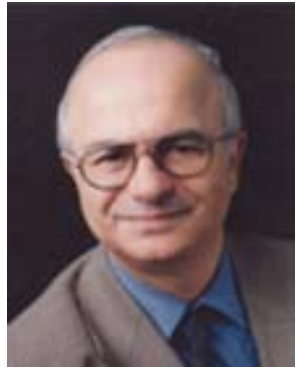

Erdal Panayirci

Technical Program Co-Chair Professor, Bilkent University, Turkey

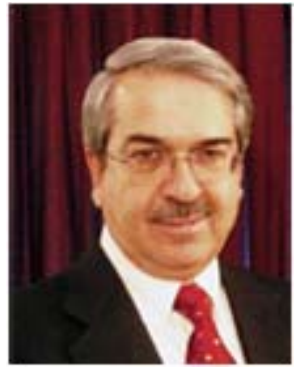

Technical Program Co-Chair Professor, Manhattan College, USA 